\title{
Chemical constituents and coagulation activity of Agastache rugosa
}

\author{
Pengran Cao ${ }^{1,2+}$, Pingyao Xie ${ }^{1 \dagger}$, Xuebiao Wang ${ }^{1}$, Jinmei Wang ${ }^{1,2}$, Jinfeng Wei ${ }^{1,2^{*}}$ and Wen-yi Kang ${ }^{1,2^{*}}$
}

\begin{abstract}
Background: In the Chinese traditional medicine, plant of Agastache rugosa (Fisch. \& C.A. Mey.) Kuntze (A. rugosa) has been used to treat nausea, vomiting and dispel damp. However, currently, few reports about the chemical constituents, especially the non-volatile components of $A$. rugosa are available.

Methods: Through separation with various column chromatographies to elucidate the chemical constituents of $A$. rugosa, the biological activities of the major constituents were investigated. The extracts and main constituents of A. rugosa were evaluated for their anticoagulant effects by assaying the activated partial thromboplastin time (APTT) , prothrombin time (PT), thrombin time (TT) and fibrinogen (FIB) in vitro.
\end{abstract}

Results: Seven known compounds (namely compounds 1-7) were isolated from the aerial parts of A. rugosa. They were identified as methyl hexadecanoate (1), $\beta$-sitosterol (2), acacetin (3), ursolic acid (4), apigenin (5), protocatechuic acid (6) and tilianin (7), respectively. Compounds 1 and 6 were isolated from the genus Agastache for the first time, and compound 4 was obtained from the plants for the first time. The results showed that the extract of $A$. rugosa had a significant procoagulant activity by shortening the time of PT $(P<0.001)$ and increasing FIB content $(P<0.001)$, as compared with Vitamin $\mathrm{K}_{1}$. While its major constituents acacetin and tilianin exhibited significant anticoagulant activities by prolonging the times of PT, APTT, $\Pi$ and reducing FIB content $(P<0.001)$, as compared with blank control group.

Conclusions: The total extract of A. rugosa possessed significant procoagulant activity, while its main components, acacetin and tilianin possessed significant anticoagulant activities. Further investigation should be pursued to find out the bioactivity components responsible for the procoagulant action of the plant.

Keywords: Agastache rugosa, Chemical composition, Coagulant activity, Acacetin, Tilianin

\section{Background}

Agastache rugosa (A. rugosa), a medicinal plant belonging to the family Lamiaceae, is native to Korea, Japan, and China. A. rugosa shows the taste and thermal properties as pungent (acrid) is slightly warm and can the channel affiliations to enter spleen, stomach and lung. $A$. rugosa has been used in folk medicine to treat a variety of diseases, including cholera, vomiting, miasma and other intestinal disorders [1-4]. According to Traditional Chinese Medicine theory, A. rugosa is classified as an aromatic and damp dissolving herb. Thus it has

\footnotetext{
* Correspondence: weijinfeng20112011@hotmail.com;

kangweny@hotmail.com

${ }^{\dagger}$ Equal contributors

${ }^{1}$ Institute of Chinese Materia Medica, Henan University, Kaifeng 475004,

China

Full list of author information is available at the end of the article
}

been widely used as an effective herbal drug to cure the diseases of human pathogenic summer-heat and dampness virulence in clinical in China.

According to the records, the use of $A$. rugosa as a medicinal plant can be traced back to the Eastern Han dynasty (25 AD - 220 AD) in China. Pharmacological investigation showed that $A$. rugosa possessed antibacterial [5], anti-HIV integration activities [6], antioxidant [7], cardiovascular $[8,9]$, cytoprotective activity and other activities $[10,11]$. Chemical studies showed that the chemical compositions of $A$. rugosa mainly contained essential oils, terpenoids, flavonoids and other constituents [11-13]. A. rugosa was collected in "Chinese Pharmacopoeia" as one of genuine medicinal materials before 1977, while "Chinese Pharmacopoeia" has only loaded Pogostemon cablin (Blanco) Benth since 1985. 
Because of this, A. rugosa was out of the scope of genuine medicinal materials, and thus the research interest in utilization of $A$. rugosa was reduced. Therefore, very few the studies on its chemical constituents and bioactivities have been available, in the recent years. In view of its abundant wild resource and diverse biological activities, it is necessary to study on its chemical constituents and to elucidate its chemical constituents and biological activities.

Thrombotic disease is a serious threat to human life and health and its incidence is ranked the highest one among various diseases. The incidence of thrombotic has still been displaying an increasing tendency. In the recent years, the studies on thrombotic disease are becoming one of the key points and hot spots in modern medicine. Drug therapy has played an important role in the prevention and treatment this disease. Currently, on the medicinal market, there are only three main types of anti-thrombotic drugs, including anticoagulant drugs, anti-platelet drugs and thrombolytic drugs. However, these drugs generally have greater adverse reactions and their prices are quiet high. Therefore, developing a safe, effective and low-cost anti thrombotic drug is an urgent need for clinical drug therapy for this disease.

Thrombosis is the proximate cause of some vascular disorders [14]. It has been shown that high-fat hyperlipidemia, obesity, hypertension, atherosclerosis, coronary heart disease, myocardial infarction, cerebral thrombosis and a series of cardiovascular and cerebrovascular diseases are associated with abnormal lipid metabolism. The main inducement include high levels of low-density lipoprotein-cholesterol (LDL-C), low levels of high density lipoprotein-cholesterol (HDL-C), the increase of free radicals and lipid peroxidation [15]. Recently, there are increasing interests in the biomedical field to isolate thrombolytic agents and anti-thrombotic compounds from food and natural sources, which are presumed to be safer and more effective. Since A. rugosa exhibits a cardiovascular protective effect, we hypothesized that $A$. rugosa may have anti-coagulation effect. A literature survey implicated that there have been no reports on the anti-coagulation activity of $A$. rugosa. Thus this study aimed to investigate the chemical constituents and the coagulation activity of $A$. rugosa.

\section{Methods}

\section{Chemicals and material}

${ }^{1} \mathrm{H}$ NMR and ${ }^{13} \mathrm{C}$ NMR spectra of chemical components of $A$. rugosa were measured on a Bruker AscendTM 400 spectrometer (Bruker Corporation, Billerica, MA, USA). Rotating evaporation instrument EYELA was purchased from Tokyo Physical and Chemical Equipment Co., Ltd. (Japan). A CXTH LC-3000 preparative HPLC system was obtained from Beijing Chuangxintongheng Science and Technology Co., Ltd. (China) and used for the highperformance column chromatography (HPLC) and equipped with binary pumps, an UV/VIS detector, and a manual injection valve. Preparative medium pressure liquid chromatographic (MPLC) separation was performed using a Sepacore glass column c-690 that was filled with Silica gel (60 mesh, 500 g). Silica gel GF 254 Thin Layer Chromatography (TLC) and Silica gel (4080 mesh, 200-300 mesh) were purchased from Yantai Huiyou Development co., Ltd (Shandong, China). Silica gel $\mathrm{H}$ was made by Qingdao Haiyang Chemical Co., Ltd (Shandong, China). Column chromatography was performed over Sephadex LH-20 (Pharmacia Kalamazoo, MI, USA). Centrifugation was performed on Shanghai Anting TGL-16gr centrifugal.

\section{Plant material}

A. rugosa (Fisch. et Mey.) O. Ktze was originally collected in October 2013 from the Suzhou region of Jiangsu Province, China and identified by Professor Changqin Li. A voucher specimen (201310231) was deposited in the Institute of Traditional Chinese Medicine, Henan University (Kaifeng, Henan, China).

\section{Extraction and isolation}

The air-dried aerial parts of $A$. rugosa $(2.8 \mathrm{Kg})$ were extracted with $70 \%$ ethanol at $50{ }^{\circ} \mathrm{C}(3 \times 15 \mathrm{~L}, 6 \mathrm{~h})$ to yield the crude extract (Ar.TE $178 \mathrm{~g}$ ) after filtration and solvent evaporation using a rotary evaporator. The extract (178 g) was dissolved in $\mathrm{H}_{2} \mathrm{O}(500 \mathrm{~mL})$, and extracted by petroleum, ethyl acetate and $n$-butanol in turn, and the recovered solvents were decompressed to obtain petroleum ether site (Ar.Pe, $11.8 \mathrm{~g}$ ), ethyl acetate part (Ar.Ea, $19 \mathrm{~g}$ ) and $n$-Butanol site (Ar.Bu, $25.2 \mathrm{~g}$ ), respectively.

Ar.Ea was separated by medium pressure liquid chromatography (MPLC) that was filled with silica gel $\mathrm{H}$, eluted with a stepwise-gradient, in sequence, of petroleum ether-ethyl acetate (100:1-1:1, v/v), chloroformmethanol (50:1-2:1, v/v) to afford 8 fractions $\left(\mathrm{F}_{1}-\mathrm{F}_{8}\right)$ based on TLC analyses. $F_{2}(1.54 \mathrm{~g})$ was subjected to decompressed chromatographic column of silica gel $\mathrm{H}$ with a gradient of petroleum ether- $\mathrm{CHCl}_{3}(1: 0-0: 1, \mathrm{v} / \mathrm{v})$ to afford 4 fractions $\left(\mathrm{F}_{2-1}-\mathrm{F}_{2-4}\right)$. The separation of $\mathrm{F}_{2-4}$ using Sephadex LH-20 (petroleum ether $/ \mathrm{CHCl}_{3} / \mathrm{MeOH}$, 9:9:2, v/v/v) successively afforded compound $\mathbf{1}(25 \mathrm{mg})$ and $F_{2-4-1} \cdot F_{2-4-1}$ was firstly subjected to ordinary pressure chromatographic columns of silica gel $\mathrm{H}$ with petroleum ether- $\mathrm{CHCl}_{3}(1: 10-0: 1, \mathrm{v} / \mathrm{v})$ and then through re-crystal to obtain compound $2(28.7 \mathrm{mg}) . \mathrm{F}_{4}(1.72 \mathrm{~g})$ was subjected to decompressed chromatographic column of silica gel $\mathrm{H}$ with petroleum ether-ethyl acetate $(40: 1-0: 1, \mathrm{v} / \mathrm{v})$ and then separated using Sephadex LH$20\left(\mathrm{CHCl}_{3} / \mathrm{MeOH}, 1: 1, \mathrm{v} / \mathrm{v}\right)$ to obtain compound 3 $(15.8 \mathrm{mg}) . \quad \mathrm{F}_{5}$ was subjected to decompressed 
chromatographic column of silica gel $\mathrm{H}$ with petroleum ether-ethyl acetate (10:1-0:1, v:v) to obtain $F_{a}$ and $F_{b}$. $F_{b}$ was subjected to decompressed chromatographic column of silica gel $\mathrm{H}$ with $\mathrm{CHCl}_{3}$-acetone $(1: 0-1: 1$, v/v) and Sephadex LH-20 $\left(\mathrm{CHCl}_{3} / \mathrm{MeOH}, 1: 1, \mathrm{v} / \mathrm{v}\right)$ to obtain compounds $3(16.3 \mathrm{mg})$ and compounds $4(33.4 \mathrm{mg})$. Compounds $3(63.8 \mathrm{mg})$ and $4(145.7 \mathrm{mg})$ were enriched in the same way from $F_{6}$ and $F_{7} . F_{7}$ was subjected to decompressed chromatographic column of silica gel $\mathrm{H}$ with $\mathrm{CHCl}_{3}$ /acetone (50:1-0:1, v:v) to obtain $\mathrm{F}_{7-1}$ and $\mathrm{F}_{7-2}$, and then $\mathrm{F}_{7-1}$ was separated using Sephadex LH-20 $\left(\mathrm{CHCl}_{3} / \mathrm{MeOH}, 1: 1, \mathrm{v} / \mathrm{v}\right)$ to obtain compound $5(3 \mathrm{mg})$. $\mathrm{F}_{7-1}$ was subjected to decompressed chromatographic column of silica gel $\mathrm{H}$ with $\mathrm{CHCl}_{3}-\mathrm{MeOH}(1: 0-1: 1, \mathrm{v} / \mathrm{v})$ and Sephadex LH-20 $\left(\mathrm{CHCl}_{3} / \mathrm{MeOH}, 1: 1, \mathrm{v} / \mathrm{v}\right)$ to obtain compound 6 (21.4 mg).

Ar.Bu was separated by MPLC that was filled with silica gel $\mathrm{H}$, eluted with $\mathrm{CHCl}_{2}-\mathrm{MeOH}(1: 0-1: 1, \mathrm{v} / \mathrm{v})$ to afford 7 parts $\left(\mathrm{P}_{1}-\mathrm{P}_{7}\right)$ based on TLC analyses. $\mathrm{P}_{1}$ was separated with Sephadex LH-20 $\left(\mathrm{CHCl}_{2} / \mathrm{MeOH}, 1: 1\right.$, v/ v) to obtain compound $3(35.8 \mathrm{mg})$. The solubility of $\mathrm{P}_{3}$ was not good. $\mathrm{P}_{3}$ was washed with petroleum ether, $\mathrm{CHCl}_{2}$, ethyl acetate, acetone and methanol and mixed solvent of various proportions, to afford un-dissolved substance compound 7 (235.3 mg).

\section{The Activated Partial thromboplastin time (APTT), Prothrombin Time (PT), Thrombin Time (TT) and Fibrinogen (FIB) Assays in Vitro}

Blood samples were drawn from Rabbit's Auricular Vein (NO: 2015-035). Before collection, the sodium citrate (38 $\mathrm{mg} / \mathrm{mL}, 400 \mu \mathrm{L}$ ) was placed in a $4 \mathrm{~mL}$ centrifuge tube to prevent blood clotting. Plasma was then separated from the blood by centrifugation at $3000 \mathrm{rpm} 5{ }^{\circ} \mathrm{C}$ for $15 \mathrm{~min}$. APTT and PT were determined according to the method described previously [16]. In brief, plasma $(100 \mu \mathrm{L})$ was mixed with $20 \mu \mathrm{L}$ of samples, APTT assay reagent $(100 \mu \mathrm{L})$ was added and incubated for $5 \mathrm{~min}$ at $37{ }^{\circ} \mathrm{C}$, and then $25 \mathrm{mM} \mathrm{CaCl}_{2}(100 \mu \mathrm{L})$ was added.
Clotting times were recorded. For PT assays, plasma $(100 \mu \mathrm{L})$ was mixed with $20 \mu \mathrm{L}$ of samples and incubated at $37{ }^{\circ} \mathrm{C}$ for $3 \mathrm{~min}$. PT assay reagent $(200 \mu \mathrm{L})$, which was hatched at $37{ }^{\circ} \mathrm{C}$ for $3 \mathrm{~min}$, was then added and clotting time was recorded. TT and FIB were determined according to the manufacturer's recommendations (Shanghai Sun Biotech Co., Ltd, China).

For all the tests mentioned above, blank solvent (dimethyl sulphoxide: Tween 80: normal saline $=2: 1: 17$ ) was used as negative control group, while the drugs of breviscapine $(13.3 \mathrm{mg} / \mathrm{mL})$ and Vitamin $K_{1}(5 \mathrm{mg} / \mathrm{mL})$ used in clinical were used as positive control groups. All the samples were dissolved in blank solvent. The concentrations of compounds were $5 \mathrm{mg} / \mathrm{mL}$ and all the extract samples were $15 \mathrm{mg} / \mathrm{mL}$. PT, APTT, TT and FIB tests were conducted by Semi-Automated Coagulation Analyzer (CPC Diagnostics Pvt. Ltd, India).

\section{Statistical analysis}

The results were expressed as the arithmetic mean plus or minus standard deviation. Numerical statistics were performed using SPSS19.0 software with single factor analysis of variance (ANOVA One-Way) to determine the significant difference. The difference between groups with $P<0.05$ and $P<0.001$ were regarded as significant and highly significant, respectively. Results were shown in Table 1.

\section{Results}

\section{Chemical constituents in $A$. rugosa}

Compound 1: was colorless oily liquid with melting point $(\mathrm{mp})$ at $28-30{ }^{\circ} \mathrm{C}$. The molecular formula was determined to be $\mathrm{C}_{17} \mathrm{H}_{34} \mathrm{O}_{2}$. EI-MS $m / z: 270[\mathrm{M}]^{+}$. ${ }^{1} \mathrm{H}-$ NMR $\left(\mathrm{CDCl}_{3}, 400 \mathrm{MHz}\right) \delta: 0.87(3 \mathrm{H}, \mathrm{t}, J=8 \mathrm{~Hz}, 4 \mathrm{~Hz}, \mathrm{H}-$ 16), $1.25(24 \mathrm{H}, \mathrm{s}, \mathrm{H}-4-15), 1.61(2 \mathrm{H}, \mathrm{m}, \mathrm{H}-3), 2.29(2 \mathrm{H}$, $\mathrm{t}, J=8 \mathrm{~Hz}, 8 \mathrm{~Hz}, \mathrm{H}-2), 3.66\left(2 \mathrm{H}, \mathrm{s}, \mathrm{H}-1^{\prime}\right) .{ }^{13} \mathrm{C}-\mathrm{NMR}$ $\left(\mathrm{CDCl}_{3}, 100 \mathrm{MHz}\right) \delta: 174.2(\mathrm{C}-1), 51.35\left(\mathrm{C}-1^{\prime}\right), 34.11$ (C-2'), 24.96 (C-3), 29.15 (C-4), 29.24 (C-5), 29.34 (C-6), 29.67 (C-7, C-11), 29.58 (C-12), 29.44 (C-13), 31.91 (C-

Table 1 The effects of A. rugosa extracts, acacetin and tilianin on APTT, PT, $\Pi$, and FIB in vitro ( $x \pm s)$

\begin{tabular}{|c|c|c|c|c|}
\hline Groups & APTT (S) & PT (S) & $\Pi(S)$ & $\mathrm{FIB}(\mathrm{g} / \mathrm{L})$ \\
\hline Blank & $19.5000 \pm 0.216$ & $11.5750 \pm 0.275$ & $14.2750 \pm 0.13$ & $3.7250 \pm 0.132$ \\
\hline Breviscapine & $22.5000 \pm 0.216^{* * *}$ & $14.0000 \pm 0.163^{* * *}$ & $20.7750 \pm 0.15^{* * *}$ & $6.1633 \pm 0.035^{* * *}$ \\
\hline Vitamin $\mathrm{K}_{1}$ & $16.5500 \pm 0.129^{* * * \# \# \#}$ & 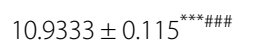 & $13.5000 \pm 0.26^{* * \# \# \#}$ & $4.6000 \pm 0.145^{* * * \# \# \#}$ \\
\hline Ar.TE & $19.3750 \pm 0.320^{\# \# \# 8 \& \&}$ & 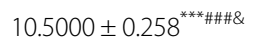 & $14.5250 \pm 0.19^{\# \# \& \& \&}$ & $6.7150 \pm 0.153^{* * * \# \# \# \& \& \&}$ \\
\hline Ar.Pe & $16.0500 \pm 0.238^{* * * \# \# \# \& \&}$ & $10.2500 \pm 0.191^{* * \# \# \# \& \& \& 8}$ & $18.6475 \pm 0.20^{* * * \# \# \# \& \& \&}$ & $3.8350 \pm 0.066^{\# \# \# \& \& \&}$ \\
\hline Ar.Ea & $16.625 \pm 0.222^{* * * \# \# \#}$ & $11.0500 \pm 0.238^{* * \# \# \#}$ & $17.2450 \pm 0.19^{* * * \# \# \# \& \& \&}$ & $3.7175 \pm 0.111^{\# \# \# \& \& \&}$ \\
\hline Ar.Bu & 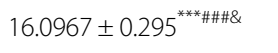 & $10.8750 \pm 0.275^{* * \# \# \#}$ & $15.2750 \pm 0.25^{* * * \& \& \&}$ & $3.9100 \pm 0.071^{* * \# \# \# \& \& \&}$ \\
\hline Acacetin & 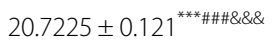 & $12.5500 \pm 0.311^{* * \# \# \# \& \& \& 8}$ & $20.2750 \pm 0.26^{* * \# \# \# \& \& \&}$ & $2.8125 \pm 0.142^{* * \# \# \# \# \& \& 8}$ \\
\hline Tilianin & 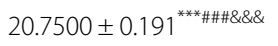 & $12.2000 \pm 0.082^{* * \# \# \# \& \& \& 8}$ & $16.7475 \pm 0.19^{* * * \# \# \# \& \& \&}$ & $3.1425 \pm 0.111^{* * * \# \# \# \& \& \&}$ \\
\hline
\end{tabular}

Note: results were expressed as mean $\pm \mathrm{SD}, n=4$. Compared with blank: ${ }^{* * *} P<0.001 ; 0.001<{ }^{* *} P<0.01 ;$ Compared with breviscapine: ${ }^{\# \# \#} P<0.001 ; 0.001<{ }^{\# \#} P<0.01$. Compared with Vitamin $\mathrm{K}_{1}: \& \& \& P<0.001,0.001<\& \& P<0.01, \& P<0.05$ 
14), 22.67 (C-15), 14.06 (C-16). The above spectral data were basically consistent with those reported previously [17] and thus, compound $\mathbf{1}$ was identified as methyl hexadecanoate.

Compound 2: this compound was a white powder with $\mathrm{mp}$ at $136-137{ }^{\circ} \mathrm{C}$. The molecular formula was determined to be $\mathrm{C}_{29} \mathrm{H}_{50} \mathrm{O}$. EI-MS $m / z: 414[\mathrm{M}]^{+}$. When compound 2 was compared with reference substance of $\beta$ sitosterol, no difference was seen between them in term of the TLC detection. Its $R_{f}$ values were the same in three different developing agents, and the coloration were the same. The samples were mixed with reference substance of $\beta$-sitosterol, and the melting point of the mixture was not decreased. Thus compound 2 was identified as $\beta$-sitosterol.

Compound 3: this compound is a yellow, needle-shaped crystal with $\mathrm{mp}$ at $261-262{ }^{\circ} \mathrm{C}$. The molecular formula was determined to be $\mathrm{C}_{16} \mathrm{H}_{12} \mathrm{O}_{5}$. EI-MS $m / z: 283[\mathrm{M}-\mathrm{H}]^{-}$. ${ }^{1} \mathrm{H}-\mathrm{NMR}\left(\mathrm{DMSO}-d_{6}, 400 \mathrm{MHz}\right) \delta: 12.88(1 \mathrm{H}, \mathrm{s}, 5-\mathrm{OH})$, $8.01\left(2 \mathrm{H}, \mathrm{d}, J=8.0 \mathrm{~Hz}, \mathrm{H}-2^{\prime}, 6^{\prime}\right), 7.11(2 \mathrm{H}, \mathrm{d}, J=8.0 \mathrm{~Hz}, \mathrm{H}-$ $\left.3^{\prime}, 5^{\prime}\right), 6.82(1 \mathrm{H}, \mathrm{s}, \mathrm{H}-3), 6.50(1 \mathrm{H}, \mathrm{s}, \mathrm{H}-8), 6.20(1 \mathrm{H}, \mathrm{s}, \mathrm{H}-$ 6), $3.84\left(3 \mathrm{H}, \mathrm{s},-\mathrm{OCH}_{3}\right) .{ }^{13} \mathrm{C}-\mathrm{NMR}\left(\mathrm{DMSO}-d_{6}, 100 \mathrm{MHz}\right)$ $\delta$ : 122.98 (C-1), 163.61 (C-2), 103.67 (C-3), 181.97 (C-4), 157.57 (C-5), 94.29 (C-6), 164.45 (C-7), 99.14 (C-8), 162.54 (C-9), 103.94 (C-10), 161.61 (C-4'), 128.52 (C$\left.2^{\prime}, 6^{\prime}\right), 114.82\left(\mathrm{C}-3^{\prime}, 5^{\prime}\right), 55.75\left(4^{\prime}-\mathrm{OCH}_{3}\right)$. The above data were basically consistent with those reported in the reference [18]. Thus, compound 3 was identified as acacetin.

Compound 4: this compound was a white crystalline with $\mathrm{mp}$ at $240-245{ }^{\circ} \mathrm{C}$. The molecular formula was determined to be $\mathrm{C}_{30} \mathrm{H}_{48} \mathrm{O}_{3}$. EI-MS $\mathrm{m} / z$ : 456[M] ${ }^{+}$. ${ }^{1} \mathrm{H}-$ NMR $\left(\mathrm{C}_{5} \mathrm{D}_{5} \mathrm{~N}, 400 \mathrm{MHz}\right) \delta: 5.50(1 \mathrm{H}, \mathrm{s}, \mathrm{H}-12), 3.46(1 \mathrm{H}$, dd, $J=4.0,8.0 \mathrm{~Hz}, \mathrm{H}-3), 2.33(1 \mathrm{H}, \mathrm{q}, \mathrm{H}-18), 1.25(3 \mathrm{H}, \mathrm{s}$, $\mathrm{H}-27), 1.24$ (3H, s, H-26), 1.06 (3H, s, H-23), 0.95 $(3 \mathrm{H}, \mathrm{d}, J=8.0 \mathrm{~Hz}, \mathrm{H}-29), 0.90$ (3H, s, H-24), $1.02(3 \mathrm{H}$, $\mathrm{d}, J=8.0 \mathrm{~Hz}, \mathrm{H}-30), 1.03(3 \mathrm{H}, \mathrm{s}, \mathrm{H}-25) .{ }^{13} \mathrm{C}-\mathrm{NMR}$ $\left(\mathrm{C}_{5} \mathrm{D}_{5} \mathrm{~N}, 100 \mathrm{MHz}\right) \delta: 37.17(\mathrm{C}-1), 27.85$ (C-2), 77.88 (C-3), 38.84 (C-4), 55.57 (C-5), 18.52 (C-6), 33.32 (C7), 39.73 (C-8), 47.78 (C-9), 39.23 (C-10), 23.64 (C11), 125.38 (C-12), 138.99 (C-13), 42.25 (C-14), 28.53 (C-15), 24.65 (C-16), 47.78 (C-17), 53.30 (C-18), 39.14 (C-19), 39.09 (C-20), 30.81 (C-21), 37.03 (C-22), 28.43 (C-23), 15.40 (C-24), 16.27 (C-25), 17.23(C-26), 23.36 (C-27), 179.55 (C-28), 17.18 (C-29), 21.11 (C-30). The above data were basically consistent with those reported in the reference [19]. Thus, compound 4 was identified as ursolic acid.

Compound 5: this compound was a yellow, needleshaped crystal with $\mathrm{mp}$ at $275-276{ }^{\circ} \mathrm{C}$. The molecular formula was determined as $\mathrm{C}_{15} \mathrm{H}_{10} \mathrm{O}_{5}$. EI-MS $\mathrm{m} /$ $z: 270[\mathrm{M}]^{-} \circ{ }^{1} \mathrm{H}-\mathrm{NMR}$ (DMSO- $\left.d_{6}, 400 \mathrm{MHz}\right) \delta$ : $12.95(1 \mathrm{H}, \mathrm{s}, 5-\mathrm{OH}), 10.81(1 \mathrm{H}, \mathrm{s}, 7-\mathrm{OH}), 10.33(1 \mathrm{H}$, s, 4' $-\mathrm{OH}), 7.91\left(2 \mathrm{H}, \mathrm{d}, J=8.0 \mathrm{~Hz}, \mathrm{H}-2^{\prime}, 6^{\prime}\right), 6.92$ $\left(2 \mathrm{H}, \mathrm{d}, J=4.0 \mathrm{~Hz}, \mathrm{H}-3^{\prime}, 5^{\prime}\right), 6.77(1 \mathrm{H}, \mathrm{s}, \mathrm{H}-3), 6.48$ $(1 \mathrm{H}, \mathrm{s}, \mathrm{H}-8), 6.19$ (1H, s, H-6). ${ }^{13} \mathrm{C}-\mathrm{NMR}$ (DMSO-d ${ }_{6}$, $100 \mathrm{MHz}) \delta$ : 164.10 (C-2), $102.83(\mathrm{C}-3), 181.72$ (C-4), 161.43 (C-5), 98.82 (C-6), 163.74 (C-7), 93.94 (C-8), 157.29 (C-9), 103.68 (C-10), 121.17 (C-1'), 128.44 $\left(\mathrm{C}-2^{\prime}, 6^{\prime}\right), 115.94$ (C-3', 5'), 161.14 (C-4'). The above data were basically consistent with those reported in reference [18]. Thus the compound $\mathbf{5}$ was identified as apigenin.

Compound 6: this compound was a yellow-brown, needle-shaped crystal with $\mathrm{mp}$ at $199-200{ }^{\circ} \mathrm{C}$. The molecular formula was determined as $(\mathrm{HO})_{2} \mathrm{C}_{6} \mathrm{H}_{3} \mathrm{COOH}$. EI-MS $m / z: 153[\mathrm{M}]^{-}$. ${ }^{1} \mathrm{H}-\mathrm{NMR}$ (DMSO- $\left.d_{6}, 400 \mathrm{MHz}\right) \delta$ : $7.33(1 \mathrm{H}, \mathrm{s}, \mathrm{H}-2), 7.29(1 \mathrm{H}, \mathrm{d}, J=8.0 \mathrm{~Hz}, 6-\mathrm{H}), 6.79(1 \mathrm{H}$, $\mathrm{d}, J=8.0 \mathrm{~Hz}, 5-\mathrm{H}) .{ }^{13} \mathrm{C}-\mathrm{NMR}$ (DMSO- $\left.d_{6}, 100 \mathrm{MHz}\right) \delta$ : 121.87 (C-1), 116.74 (C-2), 145.03 (C-3), 150.15 (C-4), 115.31 (C-5), 122.03 (C-6), 167.43 (C-7). The above data were basically consistent with those reported in the reference [20]. Thus, the compound $\mathbf{6}$ was identified as protocatechuic acid.

Compound 7: this compound was a light yellow powder with $\mathrm{mp}$ at $256-257{ }^{\circ} \mathrm{C}$. The molecular formula was determined to be $\mathrm{C}_{22} \mathrm{H}_{22} \mathrm{O}_{10}$. EI-MS $\mathrm{m} / z$ : $446[\mathrm{M}]^{+} .{ }^{1} \mathrm{H}-\mathrm{NMR}$ (DMSO- $\left.d_{6}, 400 \mathrm{MHz}\right) \delta: 12.91$ $(1 \mathrm{H}, \mathrm{s}, 5-\mathrm{OH}), 8.07\left(2 \mathrm{H}, \mathrm{d}, J=8.0 \mathrm{~Hz}, \mathrm{H}-2^{\prime}, 6^{\prime}\right), 7.14$ $\left(2 \mathrm{H}, \mathrm{d}, J=8.0 \mathrm{~Hz}, \mathrm{H}-3^{\prime}, 5^{\prime}\right), 6.95(1 \mathrm{H}, \mathrm{s}, \mathrm{H}-3), 6.86$ $(1 \mathrm{H}, \mathrm{s}, \mathrm{H}-8), 6.46(1 \mathrm{H}, \mathrm{s}, \mathrm{H}-6), 5.06(1 \mathrm{H}, \mathrm{d}, J=8.0 \mathrm{~Hz}$, Glc-H-1' $), 3.71$ (1H, m, Glc-H-2' $), 3.18$ (1H, m, Glc-H-3' $), 3.45$ (1H, m, Glc-H-4' $), 3.47$ (1H, m, Glc-H-6' 'b). ${ }^{13} \mathrm{C}-\mathrm{NMR}$ (DMSO- $\left.d_{6}, 100 \mathrm{MHz}\right) \delta$ : 163.00 (C-2), 103.78 (C-3), 181.98 (C-4), 156.93 (C-5), 99.56 (C-6), 163.80 (C-7), 94.90 (C-8), 162.44 (C-9), 105.36 (C-10), 122.66 (C-1'), 128.39 (C-2', 6'), 161.07 (C-4'), $114.59\left(\mathrm{C}-3^{\prime}, 5^{\prime}\right), 55.54\left(4^{\prime}-\mathrm{OCH}_{3}\right), 99.94\left(\mathrm{C}-2^{\prime}\right.$ '), 73.08 (C-2' '), 77.15 (C-3' '), 69.57 (C-4' '), 76.41 (C-5' '), $60.60\left(\mathrm{C}-6^{\prime \prime}\right)$. The above data were basically consistent with those reported in the reference [21]. Thus, compound 7 was identified as tilianin. All the sructures of compound $1 \sim 7$ were shown in Fig. 1 .

\section{Coagulation time test in vitro}

In Fig. 2, compared with the blank group, both acacetin and tilianin could significantly prolong APTT $(P<0.001)$ while Ar.Pe, Ar.Ea, and Ar.Bu had highly significant effects on promoting blood coagulation $(P<0.001)$. Compared with the breviscapine, the effects of acacetin and tilianin were not better than that of the positive control $(P<0.001)$. Compared with the Vitamin $K_{1}$, Ar.Pe and Ar.Bu had significant effects on promoting coagulation $(0.01<P<0.001$ and $P<0.05$, respectively).

Results shown in the Fig. 3 indicated that compared with the blank group, acacetin and tilianin could significantly prolong PT $(P<0.001)$ while Ar.TE, Ar.Pe, Ar.Ea, Ar.Bu had highly significant effects on promoting blood 


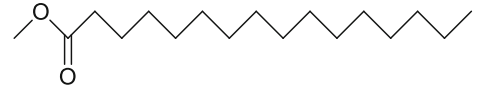

1<smiles>COc1ccc(-c2cc(=O)c3c(O)cc(O)cc3o2)cc1</smiles><smiles>O=c1cc(-c2ccc(O)cc2)oc2cc(O)c(O)cc12</smiles>

5<smiles>CCC(CC)CCC(C)C1CCC2C3CC=C4CC(O)CC[C@]4(C)C3CC[C@]12C</smiles>

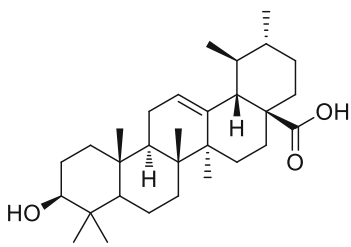

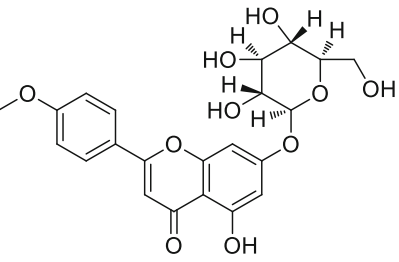

7

Fig. 1 Structures of compound $1 \sim 7$

coagulation $(P<0.001$ and $0.001<P<0.01$, respectively). Compared with the breviscapine, the effects of acacetin and tilianin were not better than the positive control $(P<0.001)$. Compared with the Vitamin $K_{1}$, Ar.TE and Ar.Pe had significant effects on promoting coagulation $(P<0.05$ and $P<0.001$, respectively).

As shown in Fig. 4, compared with the blank group, Ar.Pe, Ar.Ea, Ar.Bu, acacetin and tilianin could significantly prolong TT $(P<0.001)$. Compared with the breviscapine, the anticoagulant activity of the positive control was the best one $(P<0.001)$.

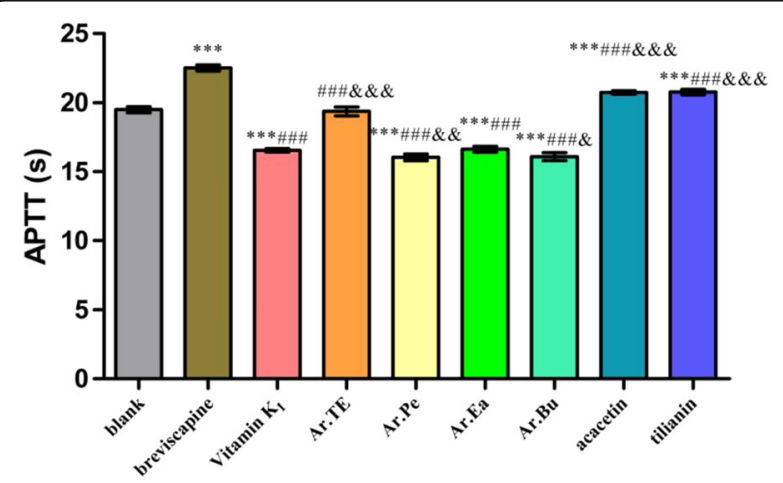

Fig. 2 The effects of A. rugosa extract, acacetin and tilianin on APTT in vitro
Results shown in the Fig. 5 indicated that compared with the blank group, acacetin and tilianin could significantly decrease the FIB content $(P<0.001)$. Compared with the Vitamin $K_{1}$, Ar.TE could significantly increase FIB content $(P<0.001)$.

\section{Discussion}

Through the chemical analysis, we found that ursolic acid, acacetin and tilianin were the main chemical components in A. rugosa. These compounds have been known to have a wide range of biological activities and play a role in triggering cardiovascular activities. For instance, Li et al. [22] reported that ursolic acid could promote the neuroprotection by activating nuclear factor-erythroid 2-related factor-2 pathway after cerebral ischemia in mice. Yang et al. [23] reported that ursolic acid could reestablish the intracellular redox state. $\mathrm{Li}$ et al. [24] demonstrated that the natural compound acacetin was an atrium-selective agent that prolonged the atrial effective refractory period without prolonging the corrected Q wave - T wave (QT) interval and effectively prevented atrial fibrillation (AF) in anesthetized dogs after intraduodenal administration. Tilianin mediated relaxation mainly by an endothelium-dependent manner, probably due to $\mathrm{NO}$ release, and also through an endothelium-independent pathway by opening $\mathrm{K}^{+}$channels, both could cause the antihypertensive effect [25]. 


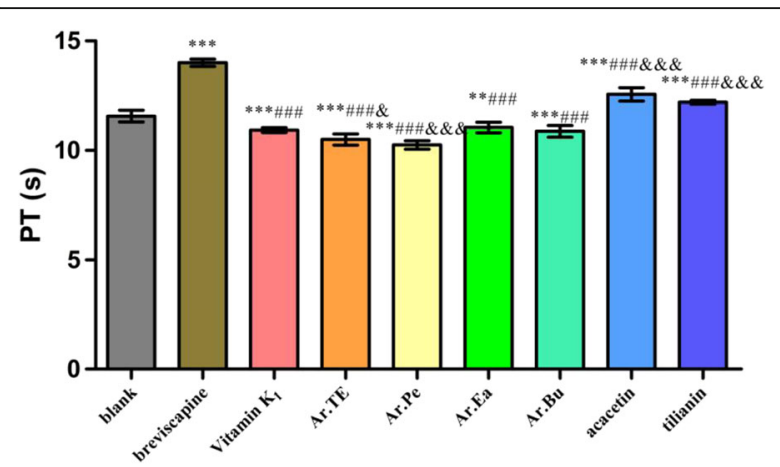

Fig. 3 The effects of A. rugosa extract, acacetin and tilianin on PT in vitro

There have been no reports in the literature about the anticoagulant activity of $A$. rugosa. In this study, we found that the main chemical components, including ursolic acid, acacetin and tilianin of $A$. rugosa had anticoagulant-related activity. Anticoagulant activities of Ar.TE, Ar.Pe, Ar.Ea, Ar.Bu, acacetin and tilianin were investigated in the experiment in vitro.

The results obtained in this study are quite interesting. Firstly, Ar.TE had an activity of promoting coagulation as shown by PT and FIB while Ar.Pe, Ar.Ea and $\mathrm{Ar} . \mathrm{Bu}$ had procoagulant activities as shown by APTT and PT. Acacetin, ursolic acid and tilianin all displayed significant anticoagulant activities as shown by PT, APTT, TT and FIB. The activities of Ar.Pe, Ar.Ea and Ar.Bu were different because their main components were different. For instance, acacetin and ursolic acid were the main components in the Ar.Ea while tilianin was one of the main components in the Ar.Bu. The difference in main components might be due to following reasons: the compounds having a great effect might not be isolated or the remaining compounds could have a great effect on promoting coagulant, though their contents might be very low. The chemical components of plant medicines are

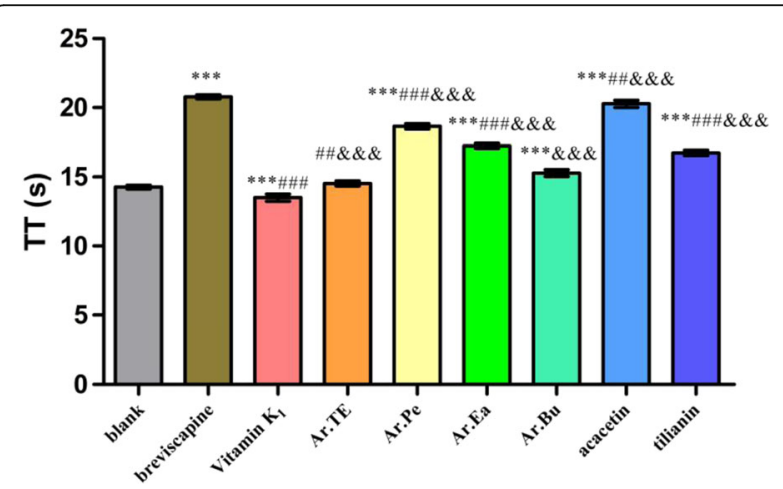

Fig. 4 The effects of $A$. rugosa extract, acacetin and tilianin on $\Pi$ in vitro

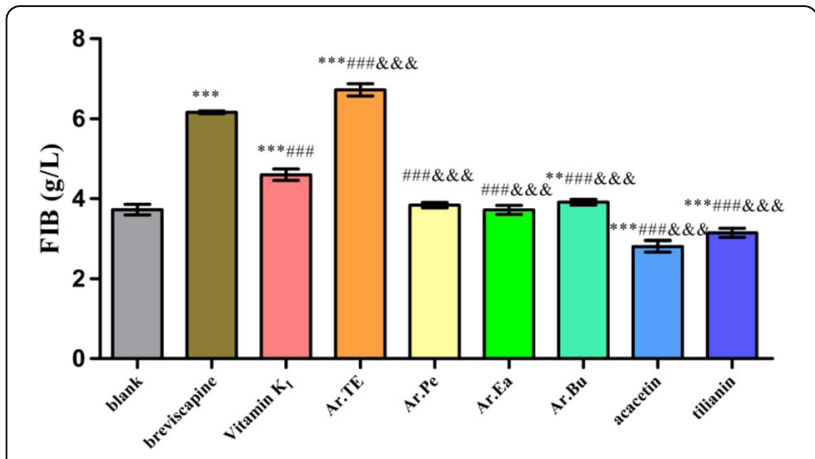

Fig. 5 The effects of $A$. rugosa extract, acacetin and tilianin on FIB in vitro

complex, and the pharmacological effects can be the interactions of multi-components, multi targets together, either synergistically or antagonistically. There might be no any compounds having great effects on promoting coagulation. This is the common function of several components.

As compared with the blank group, both acacetin and tilianin exhibited significant anticoagulant activities as demonstrated by PT, APTT, TT and FIB assays. Acacetin and tilianin are natural flavonoid compounds with abundant sources from plant origin. The techniques for isolation and separation of both compounds are simple and easy to operate. The acute toxicity experiment of acacetin showed that it was a safe clinical medication $\left(\mathrm{LD}_{50}=933 \mathrm{mg} / \mathrm{kg}\right)$ [26]. The acute toxicity test of tilianin had not been done yet and there was no report about its toxicity. Therefore, both acacetin and tilianin may have a good pharmaceutical prospect. Being cheap, safe and effective, they are in line with the requirements of today's market fort anti-thrombotic drugs. Of course, the mechanism underlying their anti-coagulation activity need to be further investigated.

A. rugosa has been commonly used to treat summer heat-dampness and stomach flu etc. Because $A$. rugosa is also an aromatic plant, the studies on $A$. rugosa have been mostly focused on the volatile components. The research on non volatile component of $A$. rugosa was mainly initiated in the 1990s [27-30], and until recently, there were have been few studies on the chemical composition and biological activity of $A$. rugosa. Thus, we investigated the chemical composition and coagulation activity of $A$. rugosa and found that Ar.TE had a significant procoagulant activity, compared with Vitamin $K_{1}$. Acacetin and tilianin had significant anticoagulant activity, as compared with the blank group. Further investigation should be pursued to find the effect of $A$. rugosa, acacetin and tilianin in vivo. Since the effects of acacetin and tilianin are different from those of $A$. rugosa, it 
should be noted that other active components in the extract remained to be further identified and characterized.

\section{Conclusions}

A. rugosa has been a traditional Chinese medicinal plant. The previous studies on $A$. rugosa were mainly focused on the volatile components and its traditional pharmacological activity. In the present study, we found for the first time that the A. rugosa had a significant coagulant activity. The total extract of $A$. rugosa possessed significant procoagulant activity while acacetin and tilianin identified as the main components of $A$. rugosa had a significant anticoagulant activity in vitro. As a novel, effective and promising drug for the treatment of various coagulation disorders, A. rugosa may be beneficial for the individual with high risks of with hemophilia and other bleeding disorders. Acacetin and tilianin were natural flavonoid compounds, whose plant origin was abundant and isolation and separation technique were simple and easy to operate. They might have a good pharmaceutical prospect. Being cheap, safe and effective, they can meet requirements of today's market about antithrombotic drugs.

\section{Acknowledgements}

This study was supported by Henan Province University Science and Technology Innovation Team (16IRTSTHN019), Key project in Science and Technology Agency of Zhengzhou City (20150341), Industry \& University Research Project in Henan Province (162107000038 and 152107000051), Basic and Advance Project in Science and Technology Agency of Henan Province (142300410123 and 152300410064), National Cooperation Project of Henan province (2015GH12) and Kaifeng City Science and Technology Innovation Talent (1509010).

\section{Funding}

This work was funded by Henan Province University Science and Technology Innovation Team (16IRTSTHN019), Industry \& University Research Project in Henan Province (162107000038 and 152107000051), Basic and Advance Project in Science and Technology Agency of Henan Province (142300410123 and 152300410064), National cooperation project of Henan province $(2015 \mathrm{GH} 12)$ and Kaifeng City Science and Technology Innovation Talent (1509010).

\section{Availability of data and materials}

The datasets supporting the conclusions of this article are presented in this main paper. Plant materials used in this study have been identified by Professor Changqin Li. A voucher specimen was deposited in the Institute of Traditional Chinese Medicine, Henan University.

\section{Authors' contributions}

WYK and JFW conceived the research idea. PRC, PYX and XBW conducted the experiment, collected the plant specimens, analyzed and interpreted the data as well as prepared the first draft. JMW identified the plants. WYK, PRC and JFW critically read and revised the paper. All the authors read and approved the paper before its final submission.

\section{Competing interests}

The authors declare that they have no competing interests.

\section{Consent for publication}

Not applicable in this section.

\section{Ethic approval and consent to participate}

The study obtained ethical clearance from the Ethics Committee of College of Medical, Henan University (NO: 2015-035). The rabbits were treated as per the guidelines on the care and use of animals for scientific purposes.

\section{Author details}

${ }^{1}$ Institute of Chinese Materia Medica, Henan University, Kaifeng 475004, China. ${ }^{2}$ Kaifeng Key Laboratory of Functional Components in Health Food, Kaifeng 475004, China.

Received: 24 May 2016 Accepted: 17 January 2017

Published online: 06 February 2017

\section{References}

1. Kim TH, Shin JH, Baek HH, Lee HJ. Volatile flavour compounds in suspension culture of Agastache rugosa Kuntze (Korean mint). J Sci Food Agr. 2001; 81(6):569-75. View Article.

2. Kebede DT, Kim GS, Kim YH, Lee WS, Lee SJ, Jin JS, et al. The polyphenolic profiles and antioxidant effects of Agastache rugosa Kuntze (Banga) flower leaf, stem and root. Biome Chromatogr. 2015;30(2):225-31 [View Article] [PubMed].

3. Lee SY, Xu H, Kim YK, Park SU. Rosmarinic acid production in hairy root cultures of Agastache rugosa Kuntze. World J Microb Biot. 2008;24(7):969-72 [View Article].

4. Li HQ, Liu QZ, Liu ZL, Du SS, Deng ZW. Chemical composition and nematicidal activity of essential oil of Agastache rugosa against Meloidogyne incognita. Molecules. 2013;18(4):4170-80 [View Article] [PubMed].

5. Shin S. Essential oil compounds from Agastache rugosa as antifungal agent against Trichophyton species. Arch Pharm Res. 2004:27(3):295-9 [PubMed].

6. Kim HK, Lee HK, Shin CG, Huh H. HIV integraseinhibitory activity of Agastache rugosa. Arch Pharm Res. 1999;22(5):520-3 [Article View] [PubMed].

7. Guo K, Xu SF, Yin P, Wang W, Song XZ, Liu FH, et al. Active components of common traditional Chinese medicine decoctions have antioxidant functions. J Anim Sci. 2011;89(10):3107-15 [PubMed].

8. Hernández-Abreu O, Torres-Piera M, García-Jiménez S, Ibarra-Barajas M, Villalobos-Molina R, Montes S, et al. Dose-dependent antihypertensive determination and toxicological studies of tilianin isolated from Agastache mexicana. J Ethnopharmacol. 2013;146(1):187-91 [View Article] [PubMed].

9. Guo X, Cao W, Yao J, Yuan Y, Hong Y, Wang X, et al. Cardioprotective effects of tilianin in rat myocardial ischemia-reperfusion injury. Mol Med Rep. 2015;11(3):2227-33 [View Article] [PubMed].

10. Wang KC, Chang JS, Chiang LC, Lin CC. 4-Methoxycinnamaldehyde inhibited human respiratory syncytial virus in a human larynx carcinoma cell line. Phytomedicine. 2009:16(9):882-6 [View Article] [PubMed].

11. Zielińska S, Matkowski A. Phytochemistry and bioactivity of aromatic and medicinal plants from the genus Agastache (Lamiaceae). Phytochem Rev. 2014;13(2):391-416 [View Article] [PubMed].

12. Lee HK, Oh SR, Kim Jl, Kim JW, Lee CO. Agastaquinone, a new cytotoxic diterpenoid quinone from Agastache rugosa. J Nat Prod. 1995;58(11):1718-21 [PubMed].

13. Tuan PA, Park WT, Xu H, Park NI, Park SU. Accumulation of tilianin and rosmarinic acid and expression of phenylpropanoid biosynthetic genes in Agastache rugosa. J Agr Food Chem. 2012;60(23):5945-51 [PubMed].

14. Choi JH, Kim DW, Park SE, Lee HJ, Kim KM, Kim KJ, et al. Anti-thrombotic effect of rutin isolated from Dendropanax morbifera Leveille. J Biosci Bioeng. 2015:120(2):181-6 [View Article] [PubMed].

15. Rajlakshmi D, Sharma DK. Hypolipidemic effect of different extracts of Clerodendron colebrookianum Walp in normal and high-fat diet fed rats. J Ethnopharmacol. 2004;90(1):63-8 [View Article] [PubMed].

16. Chen $H$, Jin M, Wang YF, Wang YQ, Meng L, Li R, et al. Effect of Toona microcarpa Harms leaf extract on the coagulation system. Biomed Res Int. 2014;2014:22-32 [View Article] [PubMed].

17. He F, Wang M, Gao M, Zhao M, Bai YH, Zhao CJ. Chemical composition and biological activities of Gerbera anandria. Molecules. 2014;19(4):4046-57 [View Article] [PubMed]

18. Ma ZK, Niu BJ, Zhang BB, Liao ZX. Chemical constituents from Pedicularis longiflora var. tubiformis. Chinese Traditional and Herbal Drugs. 2013:44(4): 403-7 [View Article]. 
19. Li HY, Jiao K, Zhang P, Gong SZ, Sun Y, Wu JZ. Chemical constituents from Isodon excisoides. Chin Tradit Herb Drugs. 2014;45(2):154-60 [View Article].

20. Jin X, Shi SM, Zhang DF, Zhu Z. Chemical constituents of Andrographis paniculata (II). Chin Tradit Herb Drugs. 2014;45(2):164-9 [View Article].

21. Xu LY, Li ZL, Cai ZC, Qian SH. Chemical constituents from Mentha haplocalyx. Chinese Traditional and Herbal Drugs. 2013;44(20):2798-802 [View Article].

22. Li LT, Zhang X, Cui LL, Wang LN, Liu HC, Ji H, et al. Ursolic acid promotes the neuroprotection by activating Nrf2 pathway after cerebral ischemia in mice. Brain Res. 2013;1497:32-9 [PubMed].

23. Yang Y, Li CW, Xiang X, Dai ZL, Chang JY, Zhang M, et al. Ursolic acid prevents endoplasmic reticulum stress-mediated apoptosis induced by heat stress in mouse cardiac myocytes. J Mol Cell Cardiol. 2014;67:103-11 [View Article] [PubMed].

24. Li G, Wang H, Qin G, Jin M, Tang $\mathrm{Q}$, Sun $\mathrm{H}$, et al. Acacetin, a natural flavone, selectively inhibits human atrial repolarization potassium currents and prevents atrial fibrillation in dogs. Circulation. 2008;117(19):2449-57 [PubMed].

25. Hernández-Abreu O, Castillo-España P, León-Rivera I, Ibarra-Barajas M, Villalobos-Molina R, González-Christen J, et al. Antihypertensiveand vasorelaxant effects of tilianin isolated from Agastache Mexicana are mediated by NO/cGMP pathway and potassium channel opening. Biochem Pharmacol. 2009;78(1):54-61 [View Article] [PubMed].

26. Cho HI, Park JH, Choi HS, Kwak JH, Lee DU, Lee SK, et al. Protective mechanisms of acacetin against $\mathrm{d}$-Galactosamine and lipopolysaccharide induced Fulminant Hepatic Failure in Mice. J Nat Prod. 2014;77(11): 2497-503 [View Article] [PubMed].

27. Lee $\mathrm{CH}$, Kim HN, Kho YE. Agastinol and agastenol, novel lignans from Agastache rugosa and their evaluation in an apoptosis inhibition assay. J Nat Prod. 2002;65(3):414-6 [View Article] [PubMed]

28. Itokawa H, Suto K, Takeya K. Structures of isoagastachoside and agastachin new glucosylflavones isolated from Agastache rugosa. Chem Pharm Bull. 1981:29(6):1777-9 [View Article].

29. Zou ZM, Cong PZ. Studies on the chemical constituents from roots of Agastache rugosa. Acta Pharmacol Sin. 1991;26(12):906-10 [View Article] [PubMed].

30. Ishitsuka H, Ohsawa C, Ohiwa T, Umeda I, Suhara Y. Antipicornavirus flavone Ro 09-0179. Antimicrob Agents Ch. 1982;22(4):611-6 [View Article] [PubMed].

\section{Submit your next manuscript to BioMed Central and we will help you at every step:}

- We accept pre-submission inquiries

- Our selector tool helps you to find the most relevant journal

- We provide round the clock customer support

- Convenient online submission

- Thorough peer review

- Inclusion in PubMed and all major indexing services

- Maximum visibility for your research

Submit your manuscript at www.biomedcentral.com/submit

) Biomed Central 